Old Dominion University

ODU Digital Commons

Electrical \& Computer Engineering Faculty

Publications

Electrical \& Computer Engineering

2015

\title{
Temporary Bonding with Polydimethylglutarimide Based Lift Off Resist as a Layer Transfer Platform
}

\author{
T. Matsumae \\ Old Dominion University
}

A. D. Koehler

J. D. Greenlee

T. J. Anderson

H. Baumgart

Old Dominion University, hbaumgar@odu.edu

See next page for additional authors

Follow this and additional works at: https://digitalcommons.odu.edu/ece_fac_pubs

Part of the Engineering Physics Commons, and the Power and Energy Commons

\section{Original Publication Citation}

Matsumae, T., Koehler, A. D., Greenlee, J. D., Anderson, T. J., Baumgart, H., Jernigan, G. G., . . Kub, F. J. (2015). Temporary bonding with polydimethylglutarimide based lift off resist as a layer transfer platform. ECS Journal of Solid State Science and Technology, 4(7), P190-P194. doi:10.1149/2.0031507jss

This Article is brought to you for free and open access by the Electrical \& Computer Engineering at ODU Digital Commons. It has been accepted for inclusion in Electrical \& Computer Engineering Faculty Publications by an authorized administrator of ODU Digital Commons. For more information, please contact digitalcommons@odu.edu. 


\section{Authors}

T. Matsumae, A. D. Koehler, J. D. Greenlee, T. J. Anderson, H. Baumgart, G. G. Jernigan, K. D. Hobart, and F. J. Kub 


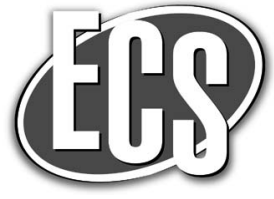

\title{
Temporary Bonding with Polydimethylglutarimide Based Lift Off Resist as a Layer Transfer Platform
}

\author{
T. Matsumae, ${ }^{a, z}$ A. D. Koehler, ${ }^{b}$ J. D. Greenlee, ${ }^{c}$ T. J. Anderson, ${ }^{b}, *$ H. Baumgart, ${ }^{a, *}$

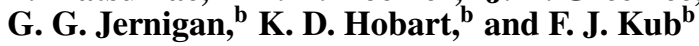 \\ ${ }^{a}$ Department of Electrical and Computer Engineering, Old Dominion University, Norfolk, Virginia 23529, USA \\ ${ }^{b}$ U. S. Naval Research Laboratory, Washington, DC 20375, USA \\ ${ }^{c}$ NRC Postdoctoral Fellow Residing at NRL, Washington, DC 20375, USA
}

\begin{abstract}
Bonding of lift off resist (LOR) was performed to realize temporary wafer bonding without residue. Bonding process conditions such as spin speed, pre-bake temperature, and bonding temperature were optimized to obtain a large bonded area with high bond strength. Under optimized process conditions, a bonded area covering over $98 \%$ of the wafer surface, with a room temperature bond strength of nearly $5 \mathrm{~J} / \mathrm{m}^{2}$ is achieved. During razor blade testing, fracture often occurs at the $\mathrm{Si}$ wafer. Moreover, debonding using an N-Methyl-2-pyrrolidone (NMP)-based solvent left the wafer surface extremely small amount of residue. Thus, the optimized bonding processed developed in this research is suitable for a clean temporary bonding process.

(c) The Author(s) 2015. Published by ECS. This is an open access article distributed under the terms of the Creative Commons Attribution 4.0 License (CC BY, http://creativecommons.org/licenses/by/4.0/), which permits unrestricted reuse of the work in any medium, provided the original work is properly cited. [DOI: 10.1149/2.0031507jss] All rights reserved.
\end{abstract}

Manuscript submitted March 4, 2015; revised manuscript received March 29, 2015. Published April 14, 2015.

As transistor scaling approaches fundamental limits, advancements in future semiconductor technology requires novel technologies such as 3D stacking of integrated circuits and novel material integration, such as graphene and other $2 \mathrm{D}$ materials. Temporary wafer bonding is a key requirement in 3D integration and is also critical for transfer of 2D materials, such as graphene. ${ }^{1-3}$ Lift-off resists (LOR) are based on polydimethylglutarimide (PMGI) and are traditionally used as sacrificial layer for undercutting during lift-off processing. However, it has recently been demonstrated that a sacrificial layer of LOR (MicroChem) implemented between graphene and photoresist enables a clean graphene surface, free of residue, after photolithographic processing and suitable for graphene transfer processes. ${ }^{4}$ The ability of LOR to maintain surface cleanliness is appealing for use as a temporary wafer bonding adhesive. Also, bonding of various types of polymer layers have been reported, such as BCB, ${ }^{5,6}$ Nafion, ${ }^{7}$ SU-8, ${ }^{8}$ Polyimide, ${ }^{9}$ and Parylene ${ }^{10}$ using wafer bonding technology. The practicability of LOR as a temporary wafer bond adhesive is investigated by systematically varying critical parameters, such as LOR deposition spin speed, pre-bake temperature, and bonding temperature.

\section{Experimental}

Bonding of LOR layers is performed to realize a temporary wafer bond suitable for 3D integrated circuits and LOR-based transfer technique of 2D materials. Figure 1 shows the procedure for LOR-toLOR bonding. First, Si wafers are cleaned using Standard Clean 1 $\left(\mathrm{H}_{2} \mathrm{O}: \mathrm{NH}_{4} \mathrm{OH}: \mathrm{H}_{2} \mathrm{O}_{2}=5: 1: 1\right)$ to remove surface contamination and to enhance LOR adhesion to the Si surface. There is still some native oxide remaining on the $\mathrm{Si}$ wafers when you start spin on coating. After surface cleaning, 2-inch diameter Si wafers are spin coated with LOR $5 \mathrm{~A}$ (MicroChem). Varying the spin speed results in varying film thicknesses, for example 2000-5000 rpm results in LOR film thicknesses of 7000-4200 nm, respectively. ${ }^{11}$ The relation between spin speed and LOR film thickness is listed in Table I. Next, the coated Si wafers are pre-baked to evaporate cyclopentanone, the solvent in LOR. Finally, the two LOR surfaces are brought into contact and introduced into an EV-501 from EVGroup Inc. bonding machine. This bonder enables thermo-compression bonding in vacuum, at $\sim 10^{-3} \mathrm{~Pa}$. LOR spinning speed, pre-bake temperature after coating, and temperature at bonding step were optimized to create a large bonded area with strong bonding.

${ }^{*}$ Electrochemical Society Active Member.

${ }^{\mathrm{z} E}$-mail: takashi.mtm@gmail.com
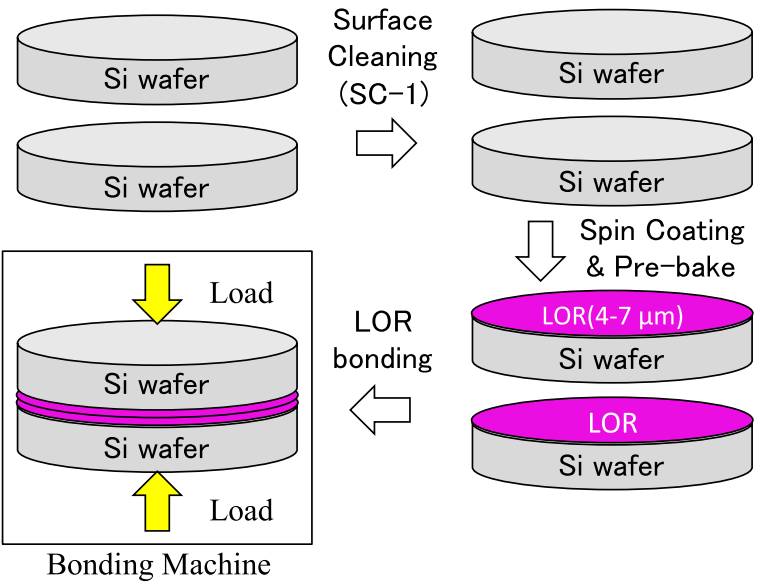

Bonding Machine

Figure 1. Experimental procedure of LOR bonding process sequence. LOR layers are formed on clean Si wafers, and bonded via applying heat and pressure in vacuum.

\section{Results and Discussion}

Typical surface morphology of a LOR film on a Si sample baked at $160^{\circ} \mathrm{C}$ is shown in Figure $2 \mathrm{a}$. The roughness of the bonding surface is critical for wafer bonding, since rough surfaces lead to reduced bonded area. Surface roughness of LOR layers was investigated with a laser interferometer from Zygo. Figure 3 shows the root mean square (RMS) value of the LOR surface roughness for varying pre-bake temperatures. As can be seen from this graph, the surface roughness peaks at a bake temperature of $160^{\circ} \mathrm{C}$. Surface roughness increases for increasing temperature from $120-160^{\circ} \mathrm{C}$. The solvent in LOR 5A is cyclopentanone, which has a boiling point of $131^{\circ} \mathrm{C}$. Thus, the

Table I. Spin speed vs LOR film thickness.

Spin speed [rpm]

LOR film thickness [nm]

$\begin{array}{lc}2000 & 7000^{*} \\ 3000 & 5500 \\ 4000 & 4800 \\ 5000 & 4200\end{array}$

*This value used in the optimized conditions was confirmed by spinning, selectively etching the LOR, and confirmed by stylus profilometry. 
(a)
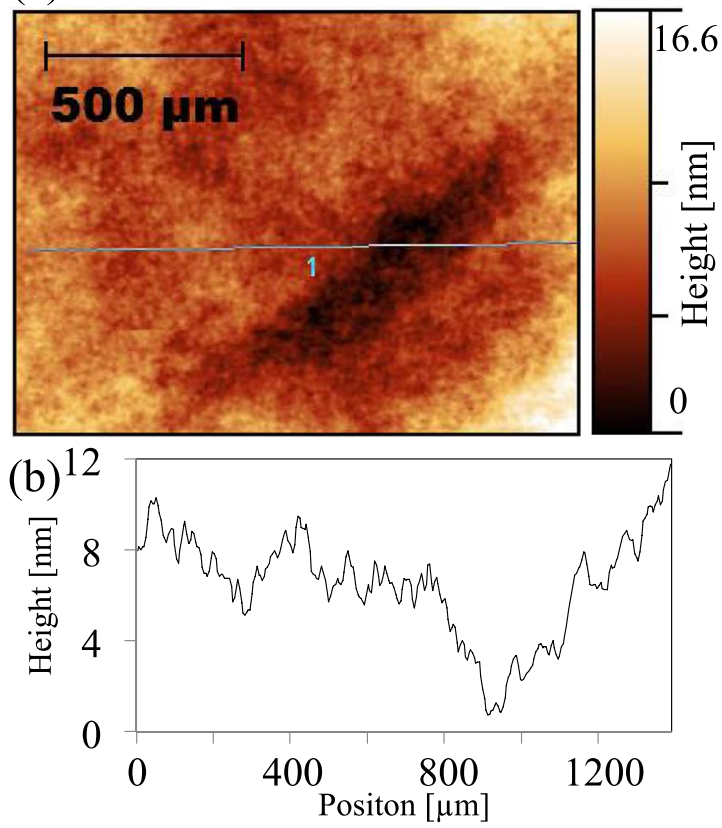

Figure 2. (a) Typical surface morphology of LOR layer measured via a Zygo laser interferometer. (b) Cross sectional roughness of LOR surface shown in the line 1 in Figure 2a.

observed surface roughness increase between $120-160^{\circ} \mathrm{C}$ is related to the solvent gradually evaporating, which leads to a corresponding loss in viscous flow. In addition, thermal expansion also likely contributes to the increasing roughness. At pre-baking temperatures exceeding $160^{\circ} \mathrm{C}$, the surface roughness decreases, since the glass transition point $\left(\mathrm{T}_{\mathrm{g}}\right)$ of PMGI is around $180-190^{\circ} \mathrm{C}$. At temperatures higher than $180^{\circ} \mathrm{C}$ beyond $\mathrm{T}_{\mathrm{g}}$, the LOR becomes much softer and the surface planarizes by viscous flow.

As shown in Figure 3, the LOR surface roughness can be modulated as a function of pre-baking temperature. However, the RMS surface roughness of all sample surfaces is around $2 \mathrm{~nm}$, which is sufficiently smooth for effective wafer bonding with polymer layers.

LOR bonding conditions were optimized for maximum bonded area and strong bonding strength by bonding of $\mathrm{Si}$ wafer pairs with LOR interlayers. The bonded area was monitored via IR camera, and the bond strength was monitored by razor blade test. ${ }^{12}$ In this study, bonding of the samples was investigated under a range of conditions including spin speed from 2000 to $5000 \mathrm{rpm}$ for 1 minutes, prebake temperature from 120 to $220^{\circ} \mathrm{C}$ for 5 minutes, and bonding temperature from 200 to $250^{\circ} \mathrm{C}$ under $750 \mathrm{KPa}$ load for 30 minutes. During bonding, the bonding machine was evacuated to a vacuum condition of around $10^{-3} \mathrm{~Pa}$ to remove residual gas and absorbed

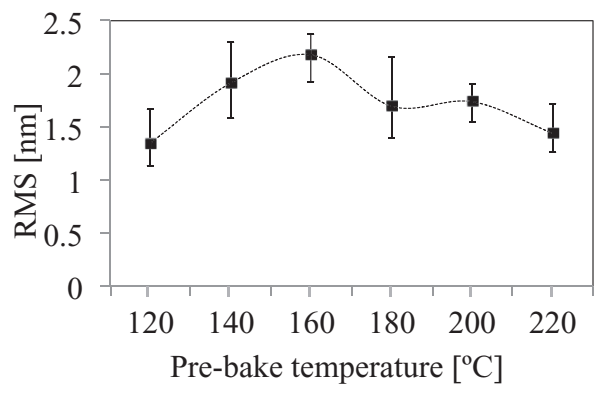

Figure 3. Relation between LOR surface roughness and pre-bake temperature.

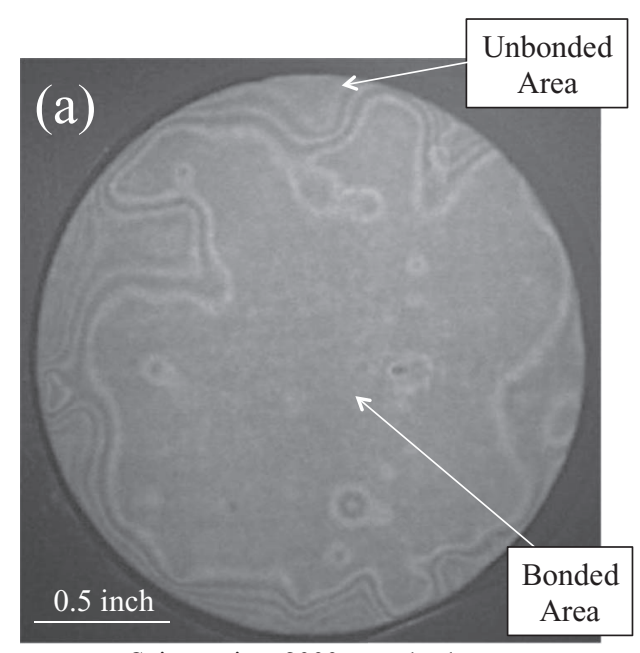

Spin coating: $2000 \mathrm{rpm}, 1 \mathrm{~min}$

Pre-bake: $160^{\circ} \mathrm{C}, 5 \mathrm{~min}$

Bonding: $200^{\circ} \mathrm{C}, 750 \mathrm{KPa}, 30 \mathrm{~min}$

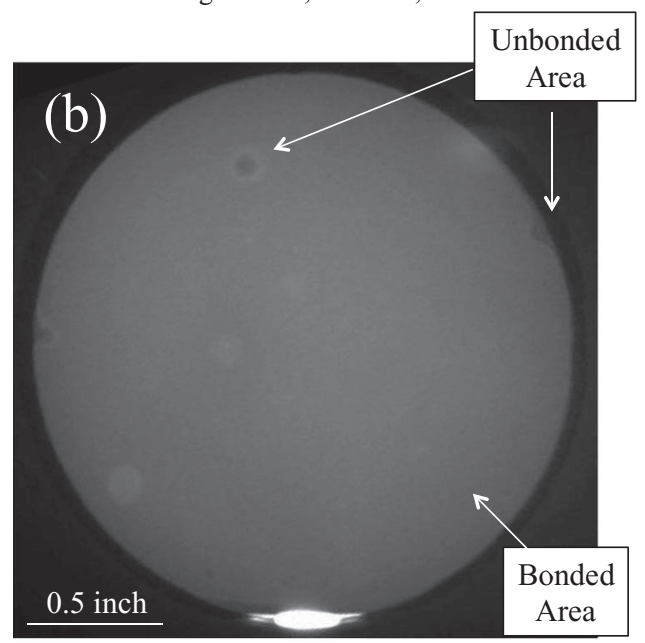

Spin coating: $2000 \mathrm{rpm}, 1 \mathrm{~min}$

Pre-bake: $160^{\circ} \mathrm{C}, 5 \mathrm{~min}$

Bonding: $250^{\circ} \mathrm{C}, 750 \mathrm{KPa}, 30 \mathrm{~min}$

Figure 4. Transmission IR images of bonded wafer pairs with LOR. These wafers are bonded under the condition of (a) not-optimized and (b) optimized condition for large bonded area as well as strong bonded interface.

volatile substances in the resist, which improves the bonding. The spin speed, pre-bake temperature, and bonding temperature of at the LOR coating were optimized to achieve large bonded area and strong bonding.

Figure $4 \mathrm{a}$ and $4 \mathrm{~b}$ show transmission IR images of bonded samples. This Figure shows a comparison of samples bonded at non-optimized conditions and at optimized conditions. The sample in Figure 4a is bonded at $200^{\circ} \mathrm{C}$, but this temperature was found to be too low. This sample exhibits large unbonded areas in particular at the edge of the wafer. On the other hand, the sample shown in Figure 4b displays a much larger bonded area and only a few voids. The sample in Figure $4 \mathrm{~b}$ was bonded at an optimized condition for large bonded area as well as strong adhesion. There are a few unbonded areas, but most of LOR surface are bonded. Some brighter spots at the lower left of Figure $4 \mathrm{~b}$ are derived from LOR resist stuck on back side of the bonded sample. The size of the bonded area was calculated via counting pixels of the IR image. At the optimized condition, over $98 \%$ of loaded area was bonded. The optimized condition is listed in Table II.

The dependence of the bonded area and the bond strength on each experimental parameter such as spin speed, pre-bake temperature, and bonding temperature has been summarized in the plots of Figure 5. 


\section{Table II. Optimized conditions for large bonded area and strong bonding with LOR resist.}

\begin{tabular}{ccc} 
Process & Parameter & Value \\
\hline Spin-coating & Spin speed & $2000 \mathrm{rpm}$ \\
& Time & $5 \mathrm{~min}$ \\
Pre-baking & Temperature & $160^{\circ} \mathrm{C}$ \\
& Time & $5 \mathrm{~min}$ \\
Bonding & Temperature & $250^{\circ} \mathrm{C}$ \\
& Load & $750 \mathrm{KPa}$ \\
& Time & $30 \mathrm{~min}$
\end{tabular}

The dotted line with triangles indicates the percentage of bonded area calculated from the IR image. The dashed line with squares indicates bond strength measured using the razor blade test. ${ }^{12}$ Since the bond strength reached nearly $5 \mathrm{~J} / \mathrm{m}^{2}$, which is near the maximum that can be measured with the blade test, ${ }^{13}$ the fracture often occurs within the $\mathrm{Si}$ wafer. This fracture in the Si bulk indicates that the LOR bonding interface and adhesion of LOR to Si surface is stronger than the $\mathrm{Si}$ bulk.

Figure 5a shows a plot of LOR spin speed versus quality of bonding. All samples in Figure 5a were bonded with the spin speed ranging from 2000 to $5000 \mathrm{rpm}$ for 1 minutes, with a pre-bake at $160^{\circ} \mathrm{C}$ for 5 minutes, and bonded at $250^{\circ} \mathrm{C}$ under $750 \mathrm{KPa}$ load for 30 minutes and a vacuum of $10^{-3} \mathrm{~Pa}$. The spin speed determines the thickness of LOR layer. Thinner LOR layers were obtained when spinning speed is high. This result shows bonded area is large enough (>98\%) at spin-
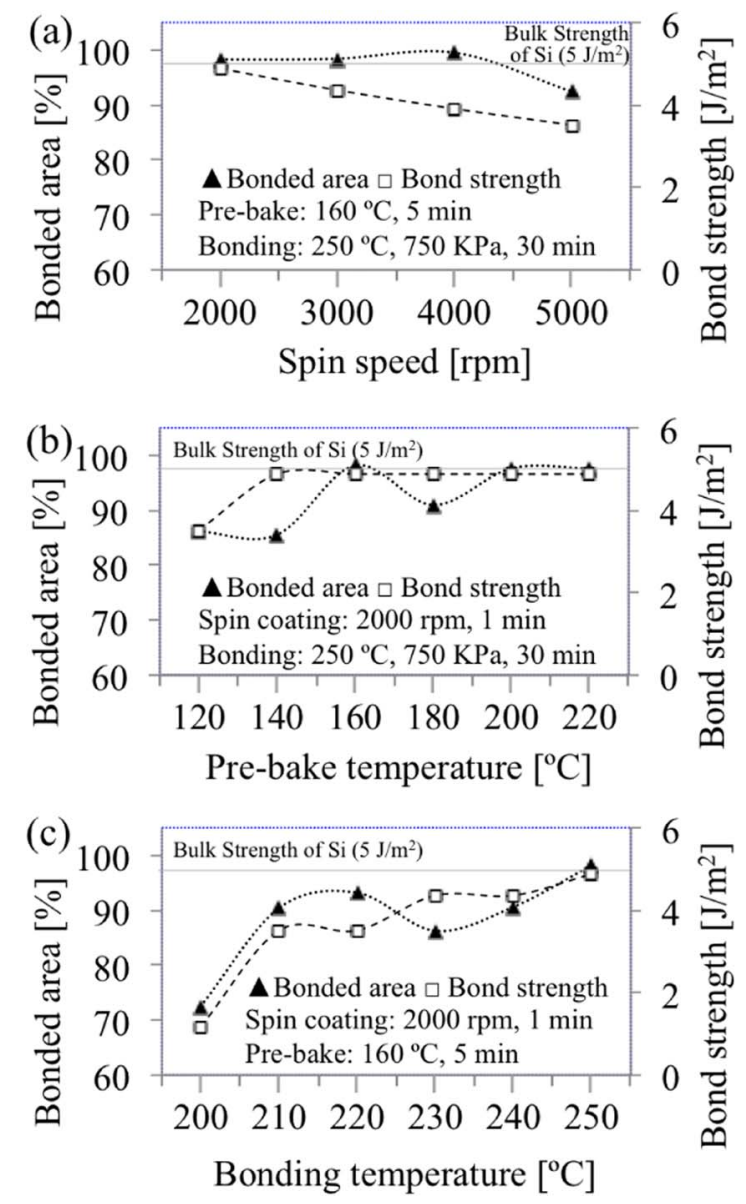

Figure 5. LOR bonding quality optimization investigated as percentage of bonded area and bond strength as a function of (a) spinning speed, (b) prebake temperature, and (c) bonding temperature. (Triangles refer to percentage of bonded area, while squares refer to the bond strength.) ning speed is between 2000-4000 rpm. However, some voids appear after bonding when spinning speed is higher than $5000 \mathrm{rpm}$ and the bond strength gradually deceased with higher spin speed corresponding to thinner LOR layers. From these results, the strongest bonding as well as largest bonded area is obtained when spin speed is 2000 $\mathrm{rpm}$. At this condition, LOR thickness is around $7 \mu \mathrm{m}$.

Figure $5 \mathrm{~b}$ shows the graph of pre-bake temperature versus quality of bonding. All samples in Figure $5 \mathrm{~b}$ were bonded under the condition of spinning $2000 \mathrm{rpm}$ for 5 minutes, pre-bake temperature from 120 to $220^{\circ} \mathrm{C}$ for 5 minutes, and bonded at $250^{\circ} \mathrm{C}$ under $750 \mathrm{KPa}$ load in 30 minutes at a vacuum condition of around $10^{-3} \mathrm{~Pa}$. As seen in the graph in Figure 5b, bonding quality of the samples baked at $120^{\circ} \mathrm{C}$ was poor in both bond strength and bonded area. However, when the prebake temperature is higher than $160^{\circ} \mathrm{C}$, most of the loaded area was bonded and the bond strength is high. One reason for this is that the boiling point of cyclopentanone, the solvent of LOR, is $131^{\circ} \mathrm{C}$. Thus, samples baked at 120 or $140^{\circ} \mathrm{C}$ still have residual solvent left in the LOR layer. Therefore, cyclopentanone vapor during bonding prevents successful bonding at the interfaces. Bonding with pre-baking over $160^{\circ} \mathrm{C}$ can achieve high quality bonding. Lower process temperature is preferable to reduce thermal damage to bonding materials, so an optimized pre-baking temperature is concluded to be $160^{\circ} \mathrm{C}$. From the result of surface profile shown in Figure 3, the LOR surface became the roughest at $160^{\circ} \mathrm{C}$ and supposedly the hardest to bond. However, the roughness of sample pre-baked at $160^{\circ} \mathrm{C}$ is $2.2+-0.2 \mathrm{~nm}$. This value is still small. Moreover, LOR surfaces are bonded at $250^{\circ} \mathrm{C}$. This temperature is higher than glass transition point $\left(T_{g}\right)$ of LOR. For these reasons, surface roughness did not play a significant role for this bonding process.

Figure $5 \mathrm{c}$ shows the graph of bonding temperature of LOR coating vs quality of bonding. All samples in Figure $5 \mathrm{c}$ were bonded under the condition of spinning $2000 \mathrm{rpm}$ for 5 minutes, pre-bake at $160^{\circ} \mathrm{C}$ for 5 minutes, and bonding temperature ranging from 200 to $250^{\circ} \mathrm{C}$ under a $750 \mathrm{KPa}$ load for 30 minutes at a vacuum of around $10^{-3} \mathrm{~Pa}$. If the bonding temperature increases, bonding across the LOR surfaces improves. From the graph in Figure $5 \mathrm{c}$, bonding quality of the samples bonded at $200^{\circ} \mathrm{C}$, which is shown in Figure. $4 \mathrm{a}$, was poor in both bond strength and the size of bonded area. However, when the bonding temperature was at least $250^{\circ} \mathrm{C}$, most of the loaded area was bonded and bond strength was higher.

Physical characterization of the bond interface of LOR wafer bonding was performed using scanning electron microscopy (SEM). Figure 6 shows the bond interface between two LOR layers on Si. The bonded Si wafer pair with LOR was cut partially using a dicing saw and cleaved to obtain cross sectional view of the bond interface. During SEM observation, the cross sectional face shown in Figure 6 was tilted by 20.4 degree from a horizontal plane in the vertical direction of Figure 6. As shown in Figure 6, original bond interface is located in center on LOR. However, after bonding no interfacial defects and

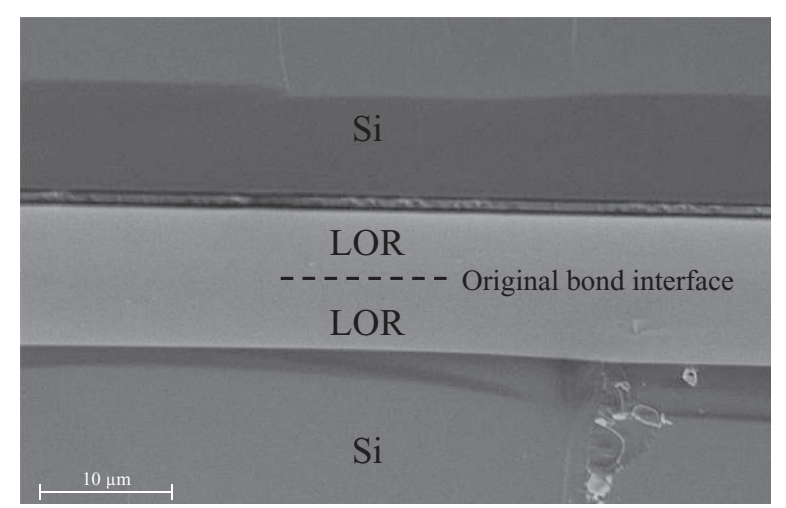

Figure 6. SEM cross-sectional micrograph of a typical cleaved bond interface of LOR bonding under a tilt angle of 20.5 degrees. This sample was prepared under the optimized conditions listed in Table II. 

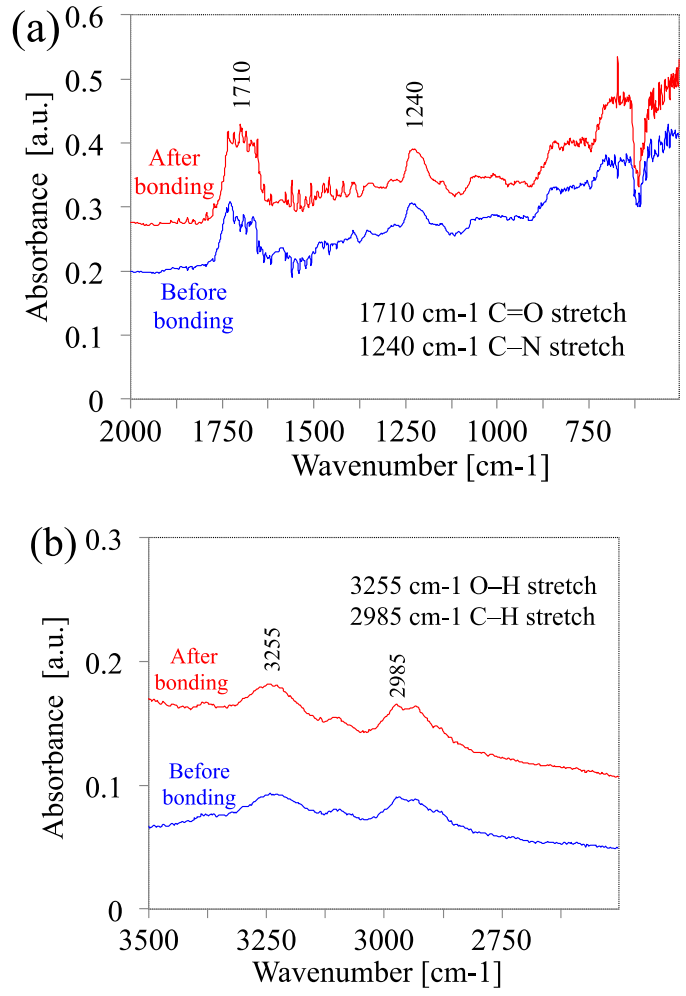

Figure 7. FT-IR absorption spectra of LOR before and after bonding process between (a) $2000-500 \mathrm{~cm}^{-1}$ and (b) $3500-2500 \mathrm{~cm}^{-1}$.

no voids were observed. Several bonded areas were observed, but no micro voids were found in the entire bonded area. Also, there was no discernable bonded interface between LOR layers. This means the original bond interface between LOR surfaces disappeared after the bonding process. Thus, the samples bonded under the optimized condition show strong bond strength.

Before bonding, the thickness of one LOR layer is $7.0 \mu \mathrm{m}$ from the LOR datasheet ${ }^{11}$ and also was confirmed via stylus profilometry. After bonding, the thickness of two bonded LOR layers is around $10 \mu \mathrm{m}$, measured by SEM. The thickness of two LOR layers before and after bonding process are $14 \mu \mathrm{m}$ and $10 \mu \mathrm{m}$, respectively. The final thickness of the LOR layer is reduced by almost $30 \%$ as a result of the bonding process.

To confirm the mechanism of film reduction during the bonding process the weight of the bonded wafers before and after bonding was measured to be $2.57126 \mathrm{~g}$ and $2.57098 \mathrm{~g}$, respectively. Weight loss during the process was $0.28 \mathrm{mg}$. The final thickness of LOR layer is reduced by almost $30 \%$, if it is caused by water loss, the weight loss is estimated to be about $8 \mathrm{mg}$. Polydimethylglutarimide (LOR) is a thermoplastic polymer and since the bonding process occurs above the glass transition temperature it is suggested that the combined films are compressed by viscous flow. The densification also helps to explain the very high bond strength that is achieved. Water is likely created during the limited crosslinking process and some of this water may escape at the elevated bonding temperature, which could explain the slight decrease in the weight of $0.28 \mathrm{mg}$. The increase in water content is supported by the FT-IR spectrum in Figure $7 \mathrm{~b}$. We conclude that the effect from polymer densification is more important than that from water loss.

In order to investigate the change in the chemical structure of LOR caused by the bonding process, Fourier transform infrared spectroscopy (FT-IR) was performed on LOR layers before and after the bonding process. Figure $7 \mathrm{a}$ and $7 \mathrm{~b}$ displays the FT-IR absorption spectra of the processed LOR layers. The sample after bonding was prepared from fractured pieces collected after the blade test. During the razor blade test, Si samples bonded under the optimized condi- tions mainly fractured inside the crystalline $\mathrm{Si}$ wafer, and some of the broken pieces after the blade test still contained the LOR layers. These LOR layers were investigated as LOR layers after the wafer bonding procedure using glancing angle reflective FT-IR. Also, the LOR sample that was spin-coated and pre-baked at same conditions as the optimized bonding conditions was investigated as a LOR layer before the wafer bonding procedure. As shown in Figure 7, both of the FT-IR spectra (a) and (b) contain some peaks originating from the PMGI. When comparing the before and after bonding spectra in Figure 7a there are a few changes observed, while in Figure $7 \mathrm{~b}$ it appears there is a slight increase in the water content after bonding. This means chemical structures before and after are not largely changed by the bonding process, indicating very limited crosslinking is occurring.

Subsequent debonding of the Si wafer pair was performed and the debonded $\mathrm{Si}$ interfaces were investigated for LOR residue. Si wafers bonded with LOR were debonded using N-Methyl-2-pyrrolidone (NMP)-based solvent called Remover PG (MicroChem). Comparison of surface roughness of the Si wafer surface before treatment and the Si wafer surface after the bonding and debonding process was performed by atomic force microscopy (AFM) in order to investigate the debonded $\mathrm{Si}$ surface for cleanliness and potential residue from LOR. The RMS of surface of before processes and after processes are $0.75 \pm 0.06 \mathrm{~nm}$ and $0.87 \pm 0.36 \mathrm{~nm}$, respectively. The size of analyzed areas was $10 \times 10 \mu \mathrm{m}^{2}$. The Si wafer surface after the debonding process is still smooth, and any residue remaining on the Si wafer surface after LOR removal is negligibly small and any resist residue can be $100 \%$ removed with a subsequent oxygen plasma ashing process. Thus polymer wafer bonding with LOR is suitable for a temporary bonding process enabling a layer transfer technology.

\section{Conclusions}

Bonding of Si wafer pairs with LOR polymer layers and debonding has been performed in order to achieve temporary bonding for applications such as 3D stacking of integrated circuits and transfer of 2D materials, such as graphene layers. Under optimized bonding conditions, LOR layers bond large areas well with high yield. Elevating the LOR polymer above the glass transition temperature $T_{g}$ proved crucial in order to allow viscous flow to achieve smoother bondable LOR surfaces. Moreover very strong bonding of $\sim 5 \mathrm{~J} / \mathrm{m}^{2}$ was achieved between two joined LOR layers, which caused fracture to occur inside the Si wafer during bond strength characterization using the razor blade test. Results of SEM investigations demonstrate that the original LOR bond interface disappears through strong mixing and chemical reactions of the polymer chains across the LOR bond interface resulting in such strong bonding. Also, the combined films are compressed during the bonding process by viscous flow. The effect from polymer densification is also important for the strong bonding. After debonding using LOR etchant remover PG, negligible residue on debonded Si wafer surface was observed. In summary, we demonstrated that LOR polymer bonding is capable of providing extremely strong bonding interfaces. Due to its chemical nature LOR polymer bonding can be considered temporary and can be readily removed with NMP based solvent for a viable debonding process. Thus temporary LOR polymer bonding and debonding can provide a platform for a layer transfer process suitable for thin layered systems like graphene or two-dimensional layered transition metal dichalcogenides like $\mathrm{MoS}_{2}$ or $\mathrm{WSe}_{2}$.

\section{References}

1. Y. Wang, C. Miao, B. C. Huang, J. Zhu, W. Liu, Y. Park, Y. H. Xie, and J. C. S. Woo, IEEE Trans. Electron Devices, 57(12), 3472 (2010)

2. J. D. Caldwell, T. J. Anderson, K. D. Hobart, G. G. Jernigan, J. C. Culbertson, F. J. Kub, J. L. Tedesco, J. K. Hite, M. A. Mastro, R. L. Myers-Ward, C. R. Eddy, P. M. Campbell, and D. K. Gaskill, MRS Proceedings, 1259 (2010)

3. R. Dong, Z. Guo, J. Palmer, Y. Hu, M. Ruan, J. Hankinson, J. Kunc, S. K. Bhattacharya, C. Berger, and W. A. de Heer, J. Appl. Phys., 47 (2014).

4. A. Nath, A. D. Koehler, G. G. Jernigan, V. D. Wheeler, J. K. Hite, S. C. Hernández, Z. R. Robinson, N. Y. Garces, R. L. Myers-Ward, C. R. Eddy, D. K. Gaskill, and M. V. Rao, Appl. Phys. Lett., 104 (2014). 
5. F. Niklaus, H. Andersson, P. Enoksson, and G. Stemme, Sensors Actuators, A Phys, 92, 235 (2001).

6. F. Niklaus, P. Enoksson, E. Kälvesten, and G. Stemme, J. Micromechanics Microengineering, 11, 100 (2001).

7. B. Ilic, P. Neuzil, T. Stanczyk, D. Czaplewski, and G. J. Maclay, Electrochem. Solid-State Lett., 2(2), 86 (1999).

8. C. T. Pan, H. Yang, S. C. Shen, M. C. Chou, and H. P. Chou, J. Micromechanics Microengineering, 12, 611 (2002).
9. A. Bayrashev and B. Ziaie, Sensors Actuators, A Phys., 103, 16 (2003).

10. H. Noh, K. Moon, A. Cannon, P. J. Hesketh, and C. P. Wong, J. Micromechanics Microengineering, 14, 625 (2004)

11. MicroChem, LOR / PMGI Data Sheet, (2008) [Revised 2015].

12. W. P. Maszara, G. Goetz, A. Caviglia, and J. B. McKitterick, J. Appl. Phys., 64, 1988, 4943 (1988)

13. F. Fournel, C. Martin-Cocher, D. Radisson, V. Larrey, E. Beche, C. Morales, P. A. Delean, F. Rieutord, and H. Moriceau, ECS Transactions, 64(5) 121 (2014). 